\title{
Optimization of cultural conditions for polygalacturonase production by a newly isolated Aspergillus fumigatus R6 capable of retting kenaf
}

\begin{abstract}
Sequential optimization strategy was used to enhance the production of extracellular polygalacturonase by a newly isolated Aspergillus fumigatus R6 using rice bran as a substrate in solid state conditions. Three significant variables influencing the polygalacturonase production were identified as initial moisture level, temperature and incubation time $(\mathrm{P}<$ $0.0001)$. The model established by face-centered central composite design was significant $(\mathrm{P}<$ $0.05)$ with high $\mathrm{R} 2$ (0.98). The model validity was verified and the optimum conditions were at an initial moisture level of $49.6 \%, 33^{\circ} \mathrm{C}$ and $129 \mathrm{~h}$ of incubation time with the maximum polygalacturonase activity of $565 \mathrm{U} / \mathrm{g}$, resulted in 2.65 fold increase in polygalacturonase activity compare to the unoptimized conditions. Kenaf stem treated with A. fumigatus R6 polygalacturonase enzyme at $72 \mathrm{~h}$ produced high strength of kenaf bast fibers (287 MPa) with high Young's modulus (10404 MPa) and the color is in satisfactory.
\end{abstract}

Keyword: Polygalacturonase; A. fumigatus; Central composite design; Solid state condition; Retting 